\title{
Effects of Endotracheal Tube Leaks on Functional Residual Capacity Determination in Intubated Neonates
}

\author{
WILLIAM W. FOX, ${ }^{(31)}$ JACOB G. SCHWARTZ, AND THOMAS H. SHAFFER \\ Division of Neonatology, Department of Pediatrics, Children's Hospital of Philadelphia; and Department of \\ Physiology, University of Pennsylvania School of Medicine, Philadelphia, Pennsylvania, USA
}

\section{Summary}

The present study evaluates a new closed circuit helium (He) dilution technique for determination of endotracheal (ET) tube leakage and functional residual capacity (FRC) in neonates with ET tubes. By analytically relating the fall in $\mathrm{He}$ concentration due to mixing with that due to leakage, it is possible to predict the final equilibration concentration of $\mathrm{He}$ and, therefore, correct for ET tube leaks. The system (120 ml) contains an air pump, He meter, breathing bag in cylinder, a strip chart readout, and solenoid valve. Continuous positive airway pressure (CPAP) or ventilator pressure can be applied during testing. FRC measurements were performed on 13 neonates (700-4500 g) on CPAP with ET tubes. Leak rates were significantly higher $(P<0.001)$ on $3 \mathrm{~cm} \mathrm{H}_{2} \mathrm{O}$ CPAP compared to $0 \mathrm{~cm} \mathrm{H}_{2} \mathrm{O}$ CPAP. The mean measured FRC was $53.5 \mathrm{ml}$ at $3 \mathrm{~cm} \mathrm{H} \mathrm{H}_{2} \mathrm{O}$ and $46.3 \mathrm{ml}$ at $0 \mathrm{~cm} \mathrm{H} \mathrm{H}_{2} \mathrm{O}$ CPAP. If gas leakage had not been considered in FRC calculations, the error in FRC could have been as high as $39 \%$ at $3 \mathrm{~cm} \mathrm{H}_{2} \mathrm{O}$ CPAP and $18 \%$ at $0 \mathrm{~cm} \mathrm{H} \mathrm{H}_{2} \mathrm{O}$ CPAP.

\section{Speculation}

The present technique provides a high degree of accuracy for determining FRC and ET tube leakage in critically ill infants on CPAP. Although measurements were not conducted on CPAP levels above $3 \mathrm{~cm} \mathrm{H}_{2} \mathrm{O}$, it is possible that higher levels of pressure may result in even greater leakage. Under these conditions FRC could only be determined accurately with this method.

Numerous clinical studies $(1,2 ; 7, .8,12,16,17,21)$ have indicated that lung volume measurement is an important factor for the evaluation of disease status and effectiveness of respiratory therapy in critically ill neonates. In the past, neonatal lung volumes such as FRC have been measured with body plethysmography, nitrogen washout curves, and He dilution methods $(3,18,19,22$, $24,27)$. However, all of these procedures require a tight-fitting face mask to prevent gas leakage from the measuring system.

A large percentage of neonates in whom lung volume determinations would provide the most clinically significant information are intubated with ET tubes and the standard face mask apparatus cannot be used. In addition, neonatal ET tubes are not cuffed and substantial gas leakage may occur, particularly during the application of continuous or intermittent positive pressure. Previous investigators have suggested the use of $\mathrm{CO}_{2}$ analyzers to sample gas from the mouth cavity during test procedures and thus qualitatively determine whether respiratory gases are leaking from around the ET tube (13). This technique does not provide a quantitative correction for gas leakage but simply an indication of its presence in which case the FRC measurement must be disregarded.

In previous study, a mathematical consideration of He leak rate was compared to in vitro experimental results to investigate the feasibility and accuracy of determining FRC in the presence of ET tube leakage (23). The present study in intubated neonates quantitates ET tube leakage and evaluates the effect of this leakage in the determination of FRC with or without CPAP.

\section{MATERIALS AND METHODS}

Thirteen infants recovering from respiratory disease and treated in the Infant Intensive Care Unit were studied after informed consent was obtained. Clinical characteristics and diagnosis are included in Table 1. Gestational age ranged from $28-42$ weeks and weights varied from $700-4500 \mathrm{~g}$. Ten of the 13 infants were recovering from the respiratory distress syndrome. Other diagnoses included pulmonary hypertension of the newborn, meconium aspiration syndrome, and tracheal esophageal fistula. Twelve of the 13 infants had received mechanical ventilation at some time during their hospitalization. Neonates in the study were intubated with nasotracheal tubes ranging from $2.5-4.0 \mathrm{~mm}$ internal diameter. Selection of tube size was based on weight, tracheal size, and experience from previous intubations in these patients. Tubes were taped securely in place. CPAP was applied with a modification of a previously described method (14) and monitored by a manometer in the system. Esophageal pressure was monitored with a soft latex balloon and polyethylene catheter to detect changes during the test procedure. FRC and ET tube leaks were sequentially determined at both $3 \mathrm{~cm} \mathrm{H}_{2} \mathrm{O}$ CPAP and $0 \mathrm{~cm} \mathrm{H}_{2} \mathrm{O}$ CPAP. Three or more determinations were made on each infant at the different levels of CPAP and were averaged. Results more than $2 \mathrm{SD}$ from the mean of the tests, reflecting large deviations in breathing patterns, were discarded.

The clinical measuring system as previously reported $(9,23)$ is diagrammed in Figure 1. The primary components of the circuit are: 1) a rubber anesthesia bag enclosed in a Plexiglas cylinder; 2) He meter (Warren E. Collins, Inc., Braintree, MA: response time less than $0.25 \mathrm{sec}$ ); 3 ) circulating air pump (Jewell Industries, Inc., Chicago, IL); and 4) a rapidly switching, silent, three-way two position solenoid valve (Fluorocarbon Solenoid Co.) for connection to the infant via ET tube or mask. Additional features of the system are a port for applying CPAP or mechanical ventilation pressure to the Plexiglas cylinder, a pre-amplifier and strip chart recorder (Texas Instruments, Inc., Houston, TX) for documenting fall in He concentration, a variable transformer for altering air pump speed, and stopcocks in the circuit for injecting gas or flushing the system. The solenoid valve was selected for silent operation, low dead space $(2.5 \mathrm{cc})$, and minimal resistance $(9.8 \mathrm{~cm}$ $\mathrm{H}_{2} \mathrm{O} /$ liter/sec).

The air pump output at different auto transformer settings was calibrated with a Collins 9 liter respirometer. All tests were run at a pump output of $1000 \mathrm{ml} / \mathrm{min}$. The strip chart recorder was set up to display in the operating He concentration range $(5-10 \%)$ of the experiments. The $\mathrm{He}$ catharometer was calibrated and cor- 
rected for any deviations in readings due to $\mathrm{O}_{2}$ or $\mathrm{CO}_{2}$ changes that occurred during the test.

The system was initially washed out and filled with an oxygen mixture corresponding to that received by the patient. The anesthesia bag was then drained by opening one of the stopcocks leaving a circuit volume of about $120 \mathrm{ml}$. One hundred percent $\mathrm{He}(15 \mathrm{ml})$ was injected into the system and $\mathrm{He}$ concentrations after equilibration were recorded (usually in the range of $12-15 \%)$. At end expiration the solenoid was switched and the infant breathed from the system for $60 \mathrm{sec}$. The baby was then switched back to the normal breathing mode. Twenty-milliliter samples of gas were then taken from the rebreathing bag and analyzed for $\mathrm{CO}_{2}$ and $\mathrm{O}_{2}$ concentrations.

FRC was determined by a modification of the basic rebreathing method (19)

$$
\mathrm{FRC}=\mathrm{V}\left(\frac{\mathrm{C}_{\mathrm{i}}}{\mathrm{C}_{\mathrm{f}}}-1\right)
$$

where $\mathrm{V}=$ known system volume, $\mathrm{C}_{\mathrm{i}}=$ initial concentration of gas in the system, and $C_{f}=$ final concentration of gas in the system.
The basic formula for calculating FRC (equation 1) was modified to take into consideration the problem of He leakage from around the ET tube (Appendix). In a closed circuit system there is an exponential fall in $\mathrm{He}$ concentration while the infant is rebreathing from the system. If there is no leak present (i.e., a tight-fitting face mask), He concentration will equilibrate rapidly as shown in Figure 2(a) and by $30 \mathrm{sec}$ the He curve should be level as in those neonates previously reported $(4,17,18)$. When there is a leak present (i.e., loose-fitting ET tube), the-curve will fall below expected equilibration values and never level off (Fig. $2(b))$. By selecting two different $\mathrm{He}$ concentrations obtained from the strip chart readout after $30 \mathrm{sec}$, it is possible to estimate the expected equilibration value $C_{f}$ as if nonleak occurred. As stated below

$$
\hat{\mathrm{C}}_{\mathrm{f}}=\mathrm{C}_{\mathrm{He}_{\mathrm{e}}\left(\mathrm{t}_{2}\right)}^{\prime}\left(\frac{\mathrm{C}_{\mathrm{He}}^{\prime}\left(\mathrm{t}_{1}\right)}{\mathrm{C}_{\mathrm{He}}^{\prime}\left(\mathrm{t}_{2}\right)}\right)\left(\frac{\mathrm{t}_{2}}{\mathrm{t}_{2}-\mathrm{t}_{1}}\right)
$$

where $t_{1}$ is the He value at $45 \mathrm{sec}$ and $t_{2}$ is the value at $60 \mathrm{sec}, \mathrm{C}_{\mathrm{He}}^{\prime}$ $\left(t_{1}\right)$ and $C_{H e}^{\prime}\left(t_{2}\right)$ are concentrations of $H e$ at times $t_{1}$ and $t_{2}$, respectively, and $\hat{C}_{f}$ is an estimator of $\mathrm{C}_{\mathrm{f}}$.

Table 1. Clinical characteristics and diagnosis

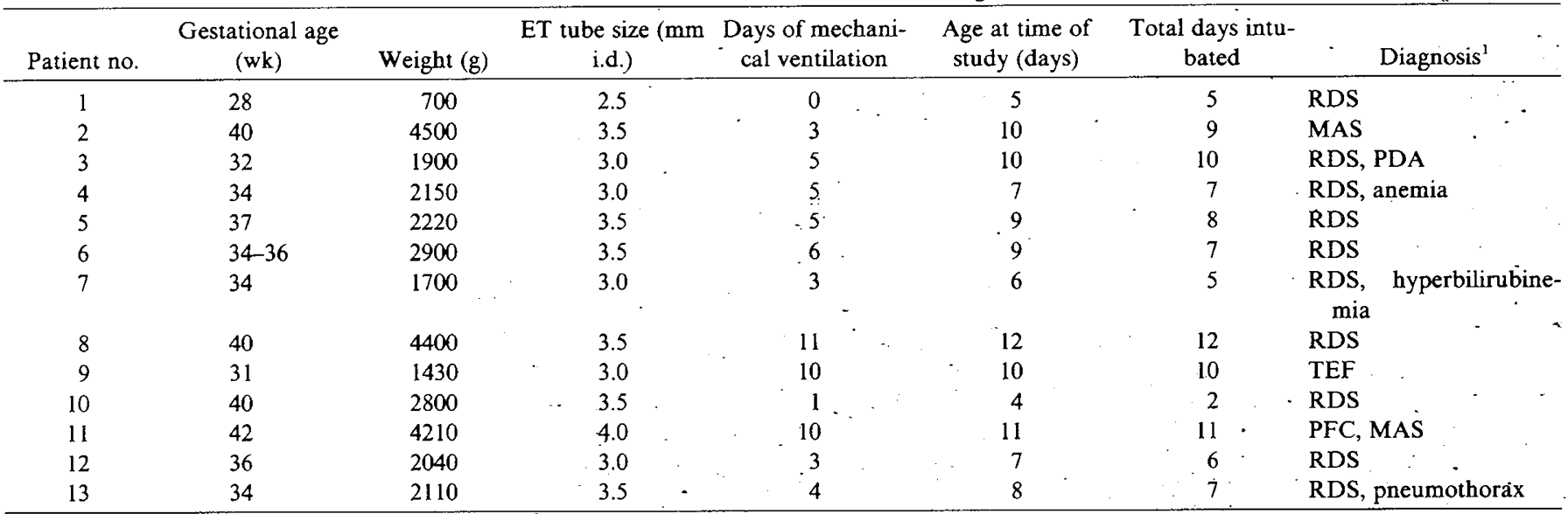

${ }^{1}$ RDS, respiratory distress syndrome; MAS, meconium aspiration syndrome; PDA, patent ductus arteriosus; TEF, tracheal esophageal fistula; and PFC, persistent fetal circulation.

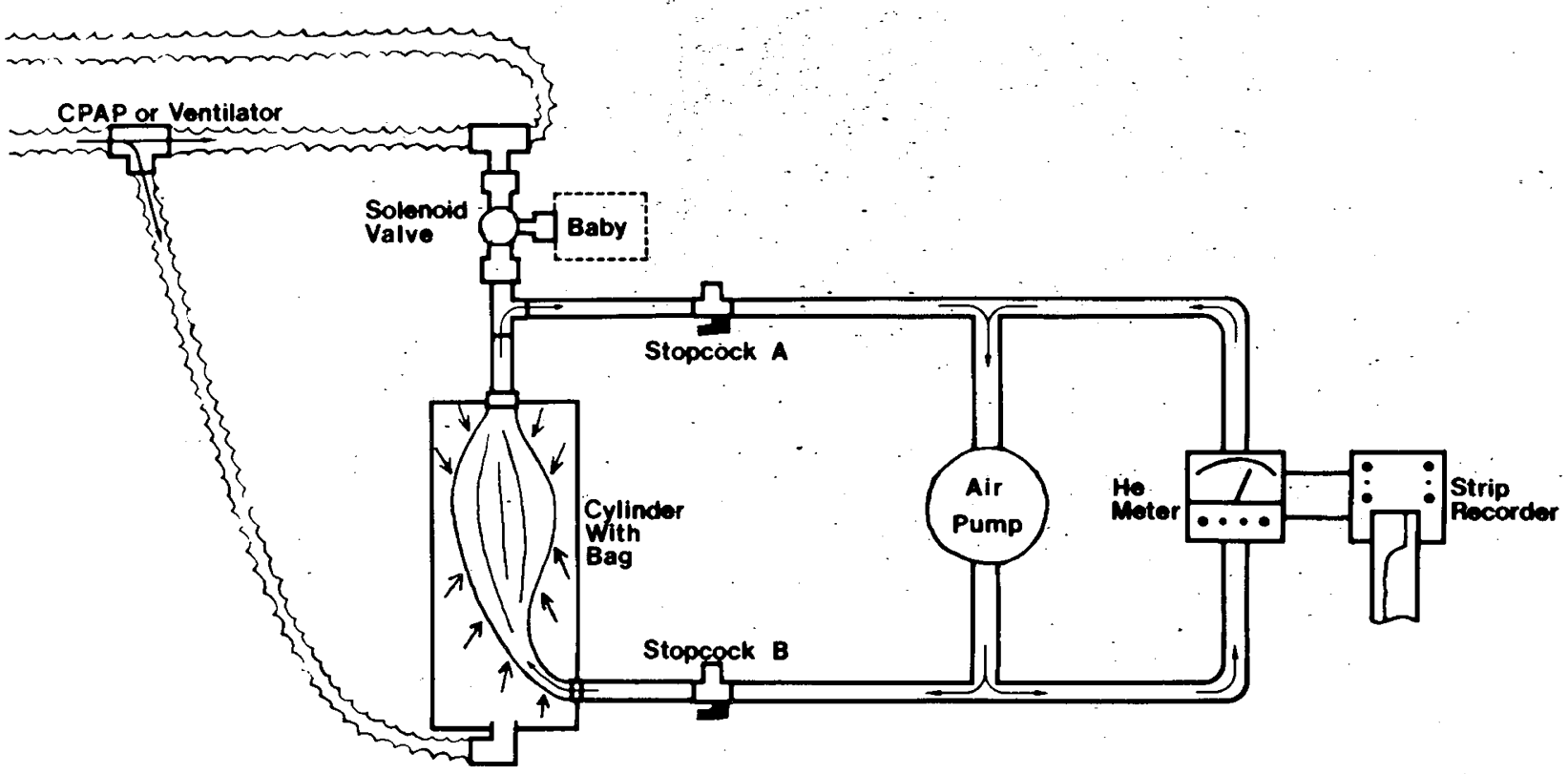

Fig. 1. Closed circuit He dilution system for measuring FRC in neonates. 

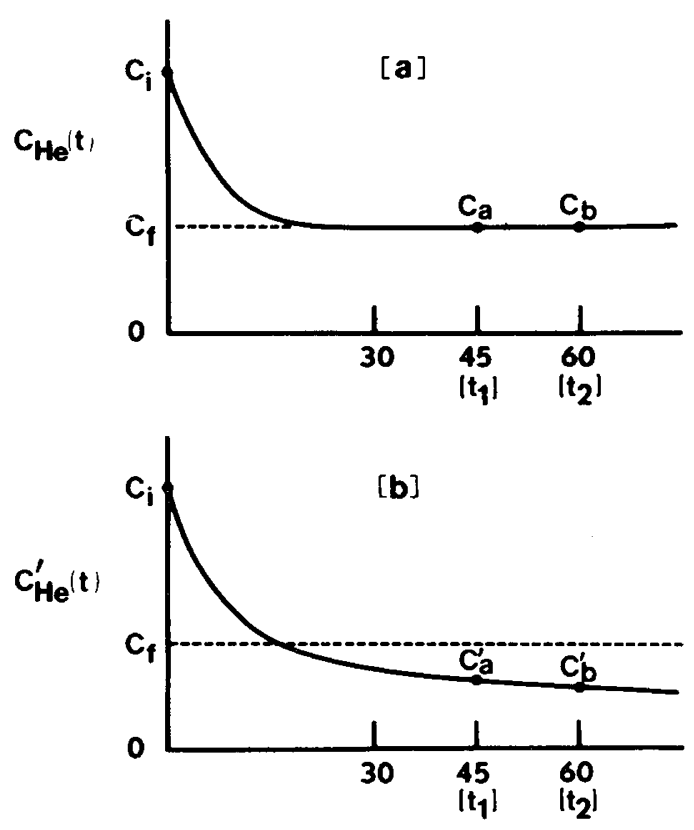

Time, seconds

Fig. 2. Theoretical He washout curve during determination of FRC: $a$, in no leak situation; $b$, in the presence of a leak.

For example, in Figure $2(b)$ the concentration of He continues to decrease during rebreathing and does not appear to equilibrate. The concentration of He at 45 and $60 \mathrm{sec}$ is $\mathrm{C}_{\mathrm{a}}$ and $\mathrm{C}_{\mathrm{b}}$, respectively. Using equation $2, \mathrm{C}_{\mathrm{f}}$ can be estimated in this simplified form as

$$
\hat{\mathrm{C}}_{\mathrm{f}}=\mathrm{C}_{\mathrm{b}}\left(\frac{\mathrm{C}_{\mathrm{a}}}{\mathrm{C}_{\mathrm{b}}}\right)^{4}
$$

In a nonleak situation in neonates (Figure $2(a)$ ) the concentration of He at 45 and $60 \mathrm{sec}$ and, therefore, final $\left(\mathrm{C}_{\mathrm{f}}\right) \mathrm{He}$ concentration would all be equal; thus, $C_{f}=C_{a}=C_{b}$.

In vitro testing of this method in 99 rebreathing trials has demonstrated close agreement $(r=0.99, P<0.001)$ between calculated and actual test volumes $(5-100 \mathrm{ml})$ in both leak and nonleak situations $(9,23)$. For this in vitro model an endotracheal tube leak was produced by inserting a $2.5-\mathrm{mm}$ internal diameter ET tube into the base of a larger ET tube. Different degrees of leaks were produced by varying the depth of insertion of the smaller tube. This experimental setup produced a continuous leak and He equilibration curves resembled those seen in experiments on neonates.

\section{RESULTS}

Functional residual capacity measurements from the neonates at 0 and $3 \mathrm{~cm} \mathrm{H}_{2} \mathrm{O}$ CPAP are shown in Figure 3. Eleven of the 13 patients demonstrated an increase in FRC at the higher level of CPAP. For the group, there was a mean rise in FRC from 45-53 $\mathrm{ml}$ as $3 \mathrm{~cm} \mathrm{H} \mathrm{H}_{2} \mathrm{O}$ CPAP was applied. During the course of each FRC measurement the strip chart readout of falling He concentration was observed and deviations from a smooth fall in concentration was used to indicate either changes in minute ventilation or breathing patterns, and records with significant variations were discarded. Only a few tests were discarded because of changes in either minute ventilation, breathing patterns, or esophageal pressure. Respiratory rates remained stable at levels as low as 30 breaths/min in some patients and as high as 70 breaths/min in others. Tidal volumes within the group ranged from $5-20 \mathrm{ml}$.

A typical tracing of He concentration during FRC determination is demonstrated in Figure 4 (patient 5). As shown, there was a rapid initial $\mathrm{He}$ equilibration lasting approximately $15 \mathrm{sec}$ (Section A). Section B or the transitional phase between helium equilibration and leakage demonstrated an irregular shape to the
He curve as a result of circulation time of the closed circuit system. In section $C$, even when experiments were run for $90 \mathrm{sec}$, there was a continuous fall in He concentrations with minor variations due to respiration.

When He concentration curves ( 25 curves for 10 neonates) were plotted on semilog paper, there were two distinct linear curves of He concentration versus time. We interpret the first part of this curve to represent the equilibration of $\mathrm{He}$ within the lungs which occurs rapidly (within 15-20 sec). The second part of the curve represents the slower decrease in $\mathrm{He}$ concentration due to a continuous He leak.

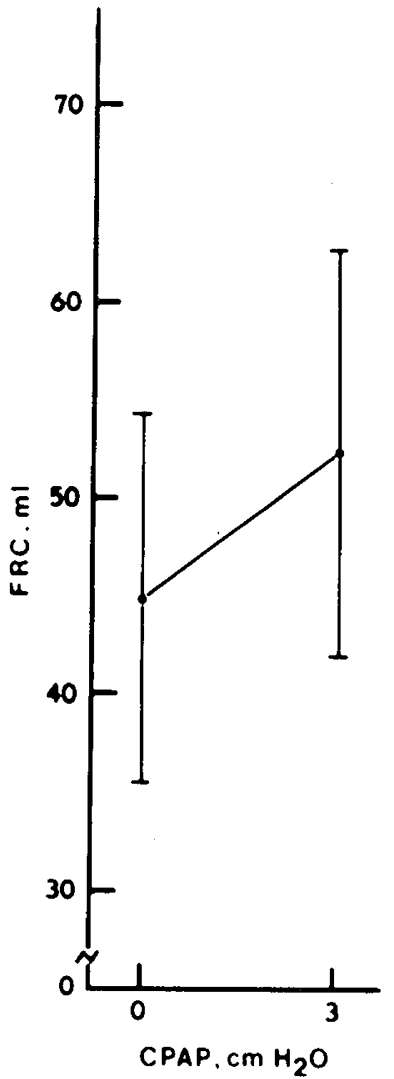

Fig. 3. FRC (mean $\pm \mathrm{SEM}$ ). measured in 13 neonates with respiratory disease at 0 and $3 \mathrm{~cm} \mathrm{H}, \mathrm{O} C P A P$.

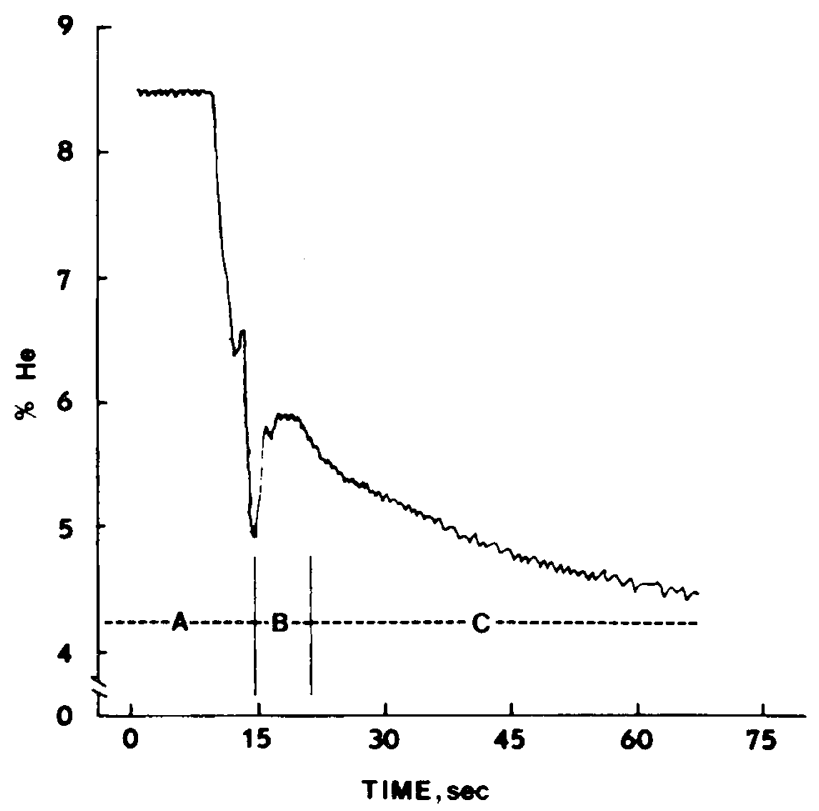

Fig. 4. Typical tracıng of He concentration during FRC determination with ET tube leakage (patient 5). 


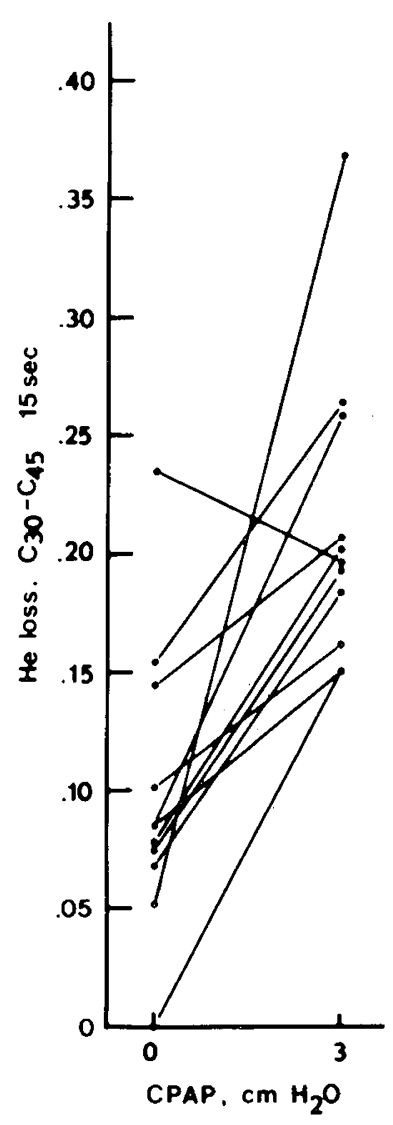

Fig. 5. ET leak rates expressed as percent loss in He concentration in $15 \mathrm{sec}$ for 13 neonates at 0 and $3 \mathrm{~cm} \mathrm{H}_{2} \mathrm{O}$ CPAP.

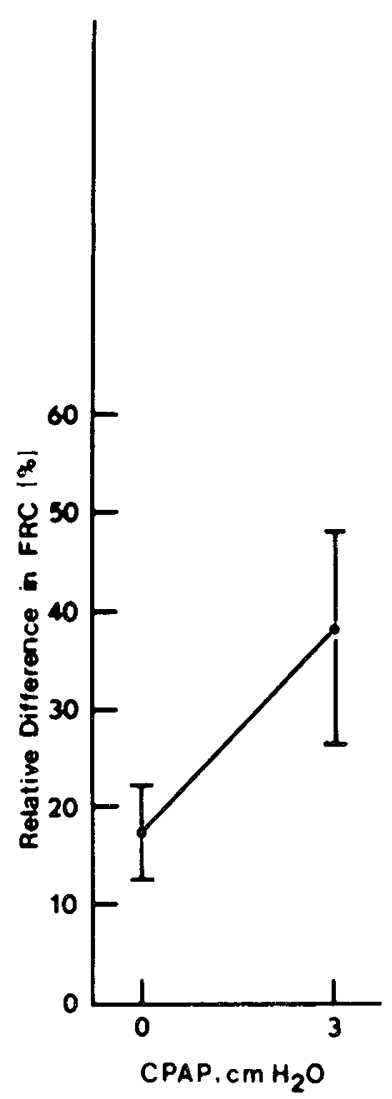

Fig. 6. Percent difference in FRC (mean \pm SEM) as calculated by the present method and by a method not considering ET tube leak.
Figure 5 illustrates the decrease in He concentration between 30 and $45 \mathrm{sec}$. There was He loss at $0 \mathrm{~cm}$ CPAP for all but one infant and this loss increased in 12 of the 13 patients when $3 \mathrm{~cm}$ $\mathrm{H}_{2} \mathrm{O}$ CPAP was applied. The mean loss of $\mathrm{He}$ for the group during $60 \mathrm{sec}$ of rebreathing was $0.61 \mathrm{ml}$ at $0 \mathrm{~cm} \mathrm{H} \mathrm{H}_{2} \mathrm{O} C P A P$ and $1.35 \mathrm{ml}$ at $3 \mathrm{~cm} \mathrm{H} \mathrm{H}_{2} \mathrm{O}$ CPAP. There was no correlation between magnitude of He loss and patient weight or endotracheal tube size. Analysis of final system volume was made on several occasions and was found to be within $5 \mathrm{ml}$ of initial volume, indicating that no significant loss of system volume occurred.

FRC calculated by previous methods [using a $30-\mathrm{sec}$ He value and without calculations for leak (17)] was compared to FRC corrected for ET tube leak (Fig. 6). At $0 \mathrm{~cm} \mathrm{H} \mathrm{H}_{2} \mathrm{O}$ CPAP there would have been $18 \%$ mean error in calculation of FRC by the rebreathing bag method if compared to the method presented here. At $3 \mathrm{~cm} \mathrm{H}_{2} \mathrm{O}$ CPAP there would have been a $39 \%$ mean error in FRC calculated by the noncirculating He method.

\section{DISCUSSION}

Previous authors have recognized the presence of ET tube gas leakage in intubated neonates and, in fact, some clinicians recommend that a small air leak should exist to prevent pressure necrosis of the tracheal mucosa (15). There is no quanlitative data in the literature concerning the magnitude of ET tube leakage, but several authors have cautioned that even small tracer gas leaks can produce significant errors in FRC calculations $(15,26)$. This study confirms and quantitates ET tube leakage; and continuous records of $\mathrm{He}$ concentration during FRC measurement demonstrated that, after the initial rapid exponential decrease in $\mathrm{He}$ concentration with rebreathing time, 12 of 13 infants continued to show a gradual fall in He concentration. The magnitude of leakage was significantly greater $(P<0.001)$ at $3 \mathrm{~cm} \mathrm{H} \mathrm{H}_{2} \mathrm{O} C P A P$ than at $0 \mathrm{~cm} \mathrm{H}{ }_{2} \mathrm{O}$ CPAP. Loss of $\mathrm{He}$ at $3 \mathrm{~cm} \mathrm{H}_{2} \mathrm{O}$ CPAP and at $0 \mathrm{~cm} \mathrm{H}_{2} \mathrm{O}$ CPAP would have resulted in respective errors in FRC of 39 and $18 \%$ if leak had not been taken into consideration. This is of specific importance because neonates with ET tubes are often the most severely ill, require the most respiratory support, and have the lowest FRC's.

The technique to measure FRC in this study provided a continuous readout of $\mathrm{He}$ equilibration during the procedure. The $\mathrm{He}$ concentration curve established information that would not have been available by only sampling initial and final He concentrations. The curve demonstrated how rapidly the initial gas equilibration occurred and indicated an index of ventilation distribution (22). Pattern variations were used to detect irregularities in equilibration due to abnormal breathing such as gasps, apnea, or tachypnea and these tests were excluded. The degree of leak was quantitated by the slope of the curve after $30 \mathrm{sec}$, and the smooth decrement of $\mathrm{He}$ concentration demonstrated a steady leak in almost all patients.

A question that concerns this method and other dilution methods for measuring FRC is whether newborns with obstructive airway disease in which the distribution of inspired oxygen is markedly abnormal can be effectively evaluated in the 60 -sec time period reported here. Some of these infants have a slow ventilation compartment as a result of partial airway obstruction and these compartments might not equilibrate during the test procedure $(5$, 22). The majority of infants in this study were recovering from respiratory distress syndrome, a nonobstructive disease. If neonates with obstructive airway disease were to be tested, a longer equilibration time may be necessary.

The noninvasive qualities of the present method make it particularly attractive for use in small infants. Neonates with several different disease processes were studied, some as small as $700 \mathrm{~g}$. In the majority of infants studied there were no appreciable changes in breathing patterns during testing. Because of the accuracy and ease of operation of the closed circuit system, we have used the FRC data for both daily patient care and clinical research studies $(10,11)$. In addition, during the evaluation of FRC each infant remains on his required CPAP, mechanical 
ventilator support, or inspired oxygen requirements; thus, paralyzed, apneic, or critically ill infants can be tested.

In addition to FRC measurements, the present method may provide information for optimum selection of ET tube size in infants on ventilators or CPAP. There have been a few suggestions about which diameter of ET tube to use in the newborn $(6,20$, 26). At present, the selection of ET tube size is made on weight and size considerations before intubation, and after viewing the vocal cords the most appropriate tube is selected for a snug fit. A small size ET tube may be less stable and irritate the trachea and a large tube may cause vocal cord stretching or damage. With the FRC method presented, one can quantitatively measure leaks and can determine whether adjustments in tube size, depth of insertion, or positioning are necessary to provide optimum therapy.

\section{CONCLUSION}

Gas leaks around the ET tubes in intubated neonates were demonstrated. Leakage varied with CPAP and, if not considered, there could have been signiticant errors in calculation of FRC. Using the method presented with a closed circuit rebreathing system and continuous $\mathrm{He}$ readout, accurate FRC was calculated even when gas leaks existed.

\section{APPENDIX}

For a nonleak procedure the concentration of He can be expressed as an exponential function of time,

$$
\mathrm{C}_{\mathrm{He}}(\mathrm{t})=\mathrm{C}_{\mathrm{f}}+\left(\mathrm{C}_{\mathrm{i}}-\mathrm{C}_{\mathrm{f}}\right)^{-\mathrm{Ft}}
$$

where $E$ is a constant of equilibration based on a one-compartment model of the lung (26).

In a procedure where a leak is present, it is assumed that the gas leaking around the ET tube is continuous and at the same concentration as the $\mathrm{He}$ in the lungs. Also, there is no net change in lung volume due to $\mathrm{He}$ loss because $\mathrm{He}$ is exchanged for ambient gas. Therefore, the amount of $\mathrm{He}$ that is lost during successive breaths can be expressed as an exponential function of time. The He concentration in the system and lungs can then be expressed as

$$
C_{\text {He }}^{\prime}(t)=\left(C_{f}+\left(C_{i}-C_{f}\right) e^{-F t}\right) e^{-\mathrm{l}, t}
$$

where $L$ is a constant of leak rate and is a function of the infant minute ventilation and the physical size of the opening between the ET tube and trachea.

Because equilibration time is essentially complete after $30 \mathrm{sec}$ (determined in infants using a face mask) $(4,17,18)$, it can be shown from equation (A-1) that for $t_{2}>i_{1}>30 \mathrm{sec}$

$$
\mathrm{C}_{\mathrm{He}}\left(\mathrm{t}_{1}\right)=\mathrm{C}_{\mathrm{He}}\left(\mathrm{t}_{2}\right)=\mathrm{C}_{\mathrm{f}}
$$

Also

$$
C_{f}+\left(C_{i}-C_{f}\right) e^{-E t_{1}}=C_{f}+\left(C_{i}-C_{f}\right) e^{-E t_{t}}=C_{f}
$$

Simplifying equation (A-4) yields

$$
\left(C_{i}-C_{f}\right) e^{-F t_{1}}=\left(C_{i}-C_{f}\right) e^{-F t_{2}}=0
$$

Combining equations (A-2) and (A-5) results in

$$
\mathrm{C}_{\mathrm{He}}^{\prime}\left(\mathrm{t}_{1}\right)=\mathrm{C}_{\mathrm{f}} \mathrm{e}^{-\mathrm{L} \mathrm{t}_{1}}
$$

and

$$
\mathrm{C}_{\mathrm{He}}^{\prime}\left(\mathrm{t}_{2}\right)=\mathrm{C}_{\mathrm{f}} \mathrm{e}^{-\mathrm{t} t_{t_{2}}}
$$

Dividing equation (A-6) by (A-7) and solving for $\mathrm{L}$ yields

$$
\mathrm{L}=\frac{1}{\mathrm{t}_{2}-\mathrm{t}_{1}} \ln \left[\frac{\mathrm{C}_{\mathrm{He}}^{\prime}\left(\mathrm{t}_{1}\right)}{\mathrm{C}_{\mathrm{He}}^{\prime}\left(\mathrm{t}_{2}\right)}\right]
$$

Finally, combining equations (A-7) and (A-8) gives an estimation of the final equilibration He concentration in a leak situation

$$
\hat{C}_{\mathrm{f}}=\mathrm{C}_{\mathrm{He}}^{\prime}\left(\mathrm{t}_{2}\right)\left[\frac{\mathrm{C}_{\mathrm{He}_{\epsilon}\left(\mathrm{t}_{1}\right)}^{\prime}}{\mathrm{C}_{\mathrm{He}}^{\prime}\left(\mathrm{t}_{2}\right)}\right]\left(\frac{\mathrm{t}_{2}}{\mathrm{t}_{2}-\mathrm{t}_{1}}\right)
$$

where $\hat{C}_{f}$ is an estimator of $\mathrm{C}_{\mathrm{f}}$.

\section{REFERENCES AND NOTES}

1. Auld. P. A. M.. Nelson. N. M.. Cherry. R. B.. Rudolph. A. J.. and Smith. C. A.: Measurement of thoracic gas volume in the newborn infant. J. Clin. Invest.. 42(4): 478 (1963).

2. Bates. D. V.. and Christie. R. V.: Intrapulmonary mixing of helium in health and in emphysema. Clin. Sci. Mol. Med.. 9: 17 (1950).

3. Berglund, G.. and Karlberg. P.: Determination of the functional residual capacity in newborn infants. Acta Pediatr.. 45: 541 (1956).

4. Berman. L. S.. Fox. W. W.. Raphael. R. C.. and Downes. J. J.: Optimum levels of CPAP for tracheal extubation of newborns. J. Pediatr.. 89: 109 (1976).

5. Briscoe. W. A.: Further studies on the intrapulmonary mixing of helium in normal and emphysematous subjects. Clin. Sci. Mol. Med.. 11: 45 (1952).

6. Chodoff, P.. and Helrich. M.: Factors affecting pediatric endotracheal tube size: A statistical analysis. Anesthesiologi; 28: 779 (1967).

7. Dubois. A. B.. Botelho. S. Y.. Bedell. G. N.. Marshall. R.. and Comroe. J. H.. Jr.: A rapid plethysmographic method for measuring thoracic gas volume: A comparison with a nitrogen washout method for measuring functional residual capacity in normal subjects. J. Clin. Invest.. 35: 322 (1956).

8. Fowler, W. S.. Cornish. E. R.. Jr.. Kety. S. S.: Lung function studies. VIII. Analysis of alveolar ventilation by pulmonary $\mathrm{N}_{2}$ clearance curves. J. Clin. Invest., 31: 40 (1952).

9. Fox. W. W.. Schwartz. J. G.. and Shaffer. T. H.: A new approach for measuring functional residual capacity (FRC) in the intubated infant. Pediatr. Res.. 11: 570 (1977).

10. Fox, W. W.. Schwartz. J. G.. and Shaffer. T. H.: Factors affecting lung volume in post extubated neonates. Pediatr. Res.. 11: 570 (1977).

11. Fox, W. W., Schwartz, J. G.. and Shaffer. T. H.: Alterations in neonatal respiratory function following chest physiotherapy. J. Pediatr.. 92: 977 (1978).

12. Geubelle, F., Karlberg, P.. Koch. G.. Lind. J.. et al.: L'aeration du poumon chez le nouveau-ne. Biol. Neonatorum. 1: 169 (1959).

13. Gregory. G. A.. Edmunds. L. H.. Jr.. Kitterman. J. A.. Phibbs. R. H.. and Tooley W. H.: Continuous positive airway pressure and pulmonary and circulatory function after cardiac surgery in infants less than three months of age. Anesthesiology. 43: 426 (1975).

14. Gregory. G. A.. Kitterman. J. A.. Phibbs. R. H.. et al.: Treatment of idiopathic respiratory distress syndrome with continuous positive airway pressure. $\mathrm{N}$ Engl. J. Med.. 284: 1333 (1971).

15. Hodson. W. A., and Belensky. D. A.: Management of Respiratory Problems. In: G. B. Avery: Neonatology. p. 265 (J. B. Lippincott Co.. Philadelphia. 1975).

16. Klaus, M., Tooley, W. H., Weaver, K. H., and Clements. J. A.: Lung volume in the newborn infant. Pediatrics, 30: 111. 1962.

17. Krauss, A. N., and Auld, P. A. M.: Measurement of functional residual capacity in distressed neonates by helium rebreathing. J. Pediatr.. 77(2): 228 (1970).

18. Krauss, A. N., and Auld. P. A. M.: Pulmonary gas trapping in premature infants. Pediatr. Res.. 5: 10 (1971).

19. Lewis. B. M., Lin. T. H.. Noe. F. E.. and Hayford-Welsing. E. J.: The measurement of pulmonary diffusing capacity for carbon monoxide by rebreathing method. J. Clin. Invest.. 38: 2073 (1959).

20. McIntyre, J. W. R.: Endotracheal tubes for children. Anesthesiology. 12: 94 (1957).

21. Nelson. N. M.. Prod'hom. L. S.. Cherry. R. B.. Lipsitz. P. J.. and Smith. C. A.: Pulmonary function in the newborn. V. Trapped gas in the normal infants lung. J. Clin. Invest.. 42(12): 1850 (1963).

22. Nye, R. E.. Jr.: Closed circuit method for measuring uneven ventilation. J. Appl. Physiol.. 16: 1109 (1961).

23. Schwartz. J. G., Fox. W. W.. and Shaffer. T. H.: A method for evaluating functional residual capacity (FRC) in neonates with endotracheal tubes. IEEE (Inst. Electr. Electron Eng.) Trans. Biomed. Eng.. 25: 304 (1978).

24. Shaffer. T. H.. Koen. P.. and Delivoria-Papadopoulos. M.: Instrumentation for measuring functional residual capacity in newborn infants and small animals. Pediatr. Res.. 11: 578 (1977).

25. Slater. H. M.. Sheridan. C. A.. and Ferguson. R. H.: Endotracheal tube sizes for infants and children. Anesthesiologr, 16: 950 (1955).

26. Strang. L. B.. and McGrath. M. W.: Alveolar ventilation in normal newborn infants studied by air wash-in after oxygen breathing. Clin. Sci. Mol. Med.. 23: 129 (1962).

27. Thibeault. D. W.. Wong. M. M.. and Auld. P. A. M.: Thoracic gas volume changes in premature infants. Pediatrics. 40(3): 403 (1967).

28. The authors are grateful to the Infant Intensive Care Unit nurses at The Children's Hospital of Philadelphia for their contribution to this study and to Miss Barbara Erwins for preparation of the manuscript.

29. The present address of Thomas H. Shaffer. Ph.D.. Department of Physiology. Temple University. School of Medicine. Philadelphia. PA 19040 (USA).

30. This research was supported in part by U.S.P.H.S. Grant HL-19402 from the National Institute of Health.

31. Requests for reprints should be addressed to: William W. Fox. M.D.. Division of Neonatology, The Children's Hospital of Philadelphia. 34th Street and Civic Center Boulevard, Philadelphia. PA 19140 (USA).

32. Received for publication August 30. 1977

33. Accepted for publication March 13. 1978. 